\title{
BMJ Open What prevents pregnant women from adhering to the continuum of maternal care? Evidence on interrelated mechanisms from a cohort study in Kenya
}

\author{
Nursena Aksünger (D) , ${ }^{1,2}$ Teresa De Sanctis (10 , ${ }^{3}$ Emma Waiyaiya, ${ }^{4}$ \\ Rianne van Doeveren, ${ }^{3}$ Mark van der Graaf, ${ }^{3}$ Wendy Janssens (D) ${ }^{1,2}$
}

To cite: Aksünger N, De Sanctis T, Waiyaiya E, et al. What prevents pregnant women from adhering to the continuum of maternal care? Evidence on interrelated mechanisms from a cohort study in Kenya. BMJ Open 2022;12:e050670. doi:10.1136/ bmjopen-2021-050670

- Prepublication history and additional supplemental material for this paper are available online. To view these files, please visit the journal online (http://dx.doi.org/10.1136/ bmjopen-2021-050670).

Received 11 March 2021 Accepted 03 December 2021

Check for updates

(C) Author(s) (or their employer(s)) 2022. Re-use permitted under CC BY-NC. No commercial re-use. See rights and permissions. Published by BMJ.

${ }^{1}$ School of Business and Economics, Vrije Universiteit Amsterdam, Amsterdam, The Netherlands

${ }^{2}$ Amsterdam Institute for Global Health and Development (AIGHD), Amsterdam, The Netherlands

${ }^{3}$ PharmAccess Foundation, Amsterdam, The Netherlands ${ }^{4}$ PharmAccess Foundation, Nairobi, Kenya

Correspondence to

Nursena Aksünger;

n.aksunger@vu.nl

\section{ABSTRACT}

Objectives To examine the determinants of the continuum of maternal care from an integrated perspective, focusing on how key components of an adequate journey are interrelated.

Design A facility-based prospective cohort study. Setting 25 health facilities across three counties of Kenya: Nairobi, Kisumu and Kakamega.

Participants A total of 5879 low-income pregnant women aged 13-49 years.

Outcome measures Ordinary least squares, Poisson and logistic regression models were employed, to predict three key determinants of the continuum of maternal care: (i) the week of enrolment at the clinic for antenatal care (ANC), (ii) the total number of ANC visits and (iii) utilisation of skilled birth attendance (SBA). The interrelationship between the three outcome variables was assessed with structural equation modeling.

Results Each week of delayed enrolment in ANC reduced the number of ANC visits by $3 \%$ (incidence rate ratio $=0.967,95 \% \mathrm{Cl} 0.965$ to 0.969 ). A higher number of ANC visits increased the relative probability of using SBA (odds ratio $=1.28,95 \% \mathrm{Cl} 1.22$ to 1.34). The direct association between late enrolment and SBA was positive (odds ratio $=1.033,95 \% \mathrm{Cl} 1.02$ to 1.04). Predisposing factors (age, household head's education), enabling factors (wealth, shorter distance, rural area) and need factors (risk level of pregnancy, multigravida) were positively associated with adherence to ANC.

Conclusion The results point towards a domino-effect and underscore the importance of enhancing the full continuum of maternal care. A larger number of ANC visits increases SBA, while early initiation of the care journey increases the number of ANC visits, thereby indirectly supporting SBA as well. These beneficial pathways counteract the direct link between enrolment and SBA, which is partly driven by pregnant teenagers who both enrol late and are at heightened risk of complications, stressing the need for specific attention to this vulnerable population.
Strengths and limitations of this study

- This study uses data recorded by health workers in real-time, providing accurate and reliable information on maternal care based on international standards during the entire care journey at health facilities.

- The target group constitutes a large, representative sample of low-income pregnant women from three different social settings, viz. urban, peri-urban and rural in Kenya.

- The study connects a baseline survey to all stages of maternal care, thereby providing granular insights into the full continuum of care at the individual level.

- The actual number of antenatal care visits and the percentage of women making use of skilled birth attendance might be underestimated as the data do not capture potential alternative locations of maternal care.

\section{INTRODUCTION}

Every 2 minutes, a pregnant woman dies somewhere in the world due to pregnancy or childbirth-related causes. ${ }^{1}$ Sub-Saharan Africa (SSA) alone accounts for over two-thirds $(68 \%)$ of all maternal deaths worldwide per year. ${ }^{2}$ SSA also has the highest lifetime risk of maternal death: the probability that a teenage woman in SSA will eventually die from a maternal cause is 1 in 38 compared with 1 in 5400 in high-income countries. ${ }^{3}$ Although the maternal mortality ratio (MMR) in SSA dropped substantially from 870 to 534 deaths per 100000 live births from 2000 to 2017 , MMR in SSA is still far below the Sustainable Development Goal target of 70 per 100000 births. ${ }^{4}$

Approximately $75 \%$ of global maternal deaths result from preventable or treatable complications, such as severe bleeding, high 
blood pressure during pregnancy, delivery complications, infections and unsafe abortion. ${ }^{5}$ Antenatal care (ANC) can reduce these avoidable maternal deaths, being effective in the prevention and treatment of anaemia, pregnancy-induced hypertension, pre-eclampsia and infections. ${ }^{6}$ Early enrolment at ANC centres also ensures that healthcare providers have enough time to support and plan a mother's journey. ${ }^{7}$ Regular ANC visits enhance the likelihood of a safe mother journey through increased awareness among women, early diagnosis and emergency preparedness. Even a 7\% increase in ANC coverage might save 160000 newborn lives annually in Africa, ${ }^{8}$ and significantly improve neonatal and infant health outcomes. ${ }^{9}$

Regular ANC visits not only reduce the risk of prenatal complications but also enable pregnant women to stay in touch with the healthcare system. This, in turn, might increase the probability of skilled birth attendance (SBA) at a formal healthcare facility, which is critical in reducing maternal mortality. ${ }^{10-12}$ Delivery in the presence of a skilled birth attendant can significantly reduce the four main obstetric complications (obstetric haemorrhage, eclampsia, obstructed labour and sepsis), reducing maternal deaths by an estimated $16 \%-33 \% .^{13}$

Accordingly, the World Health Organization (WHO) recommends a minimum of four ANC visits for an uncomplicated pregnancy, with the first one held before the 12 th week of pregnancy, ${ }^{8}$ and delivery in the presence of a skilled birth attendant to ensure adherence to scientifically proven perinatal practices. Effective linkage over the continuum of maternal care has been associated with a reduced risk of combined neonatal, perinatal and maternal mortality of $17 \% .{ }^{14}$ However, adherence to maternal care remains a challenge in SSA, where only $24.9 \%$ of pregnant women enrol in their first trimester, compared with $64.3 \%$ globally. ${ }^{7}$ Only $53.6 \%$ of pregnant women complete the recommended four ANC visits and $61.6 \%$ opt for SBA at delivery. ${ }^{15}$

This study examines what keeps pregnant women from attending the full continuum of care. In addition, it aims to highlight how the separate stages of the maternal care journey are built on each other. Although previous studies have investigated determinants of adherence to maternal care by looking at the timing of enrolment, the number of ANC visits, or the type of delivery, these factors are generally examined in isolation. To our knowledge, only one study examined these three pillars from a holistic approach. ${ }^{16}$ It found that the likelihood of adequate maternal care increased with higher education, higher wealth and low parity. However, the primary outcome in that study was 'adequate ANC use', defined as making at least four ANC visits during pregnancy, with the first visit taking place in the first trimester. As a result, it could not distinguish between the determinants of the week of enrolment and the number of visits nor estimate how these two outcomes depend on each other. Therefore, we examine the determinants of the continuum of maternal care from an integrated perspective, seeking to identify how the three key components of an adequate journey are interrelated: (i) the week of enrolment in ANC, (ii) the total number of ANC visits, and (iii) utilisation of SBA.

Several studies have identified the determinants of late ANC initiation in SSA. Delayed enrolment is associated with lower educational attainment of expectant mothers, ${ }^{17-19}$ low socioeconomic status, ${ }^{18-20}$ rural residency ${ }^{20-22}$ long-distance to a facility, ${ }^{21}{ }^{23}$ misconceptions about maternal healthcare and lack of awareness about the advantages of early ANC initiation. ${ }^{20} 2124$ On the other hand, pregnancy-related risk signs, ${ }^{17}{ }^{23}$ having a planned pregnancy ${ }^{172024}$ and low parity ${ }^{1920} 24$ contribute to early enrolment. Evidence on the effects of maternal age has been inconsistent, ${ }^{18-20}$ potentially due to the use of different age categories in the analyses.

Determinants of utilisation rates of antenatal care have long been on the research agenda. The low number of ANC visits in SSA has been associated with a low level of education of the expectant mother ${ }^{22} 25-29$ and her husband, ${ }^{10}$ low socioeconomic status, ${ }^{25} 273031$ rural residency, ${ }^{262730}$ long-distance and travel time to the clinic ${ }^{28-30}$ and cost of ANC. ${ }^{32}{ }^{33}$ Late enrolment, ${ }^{28}$ low pregnancyrelated risk and complications ${ }^{22} 2334$ and low awareness of ANC benefits ${ }^{31}$ are also negatively associated with the number of ANC visits. The evidence on maternal age and parity is inconclusive. ${ }^{2526282931}$

Previous research has shown that the probability of SBA in SSA is positively associated with a higher education level of the pregnant woman ${ }^{1235-37}$ and her husband, ${ }^{1012}$ higher socioeconomic status, ${ }^{11} 123537$ low parity, ${ }^{123135}$ living in an urban area, ${ }^{123135}$ a higher number of ANC visits, ${ }^{10-12}$ pregnancy-related complications ${ }^{31}$ and a short distance to a clinic. ${ }^{11} 3137$ However, one study from Malawi reported that urban women were less likely to use SBA than their rural counterparts, ${ }^{37}$ perhaps because women in urban slums may have limited access to maternal healthcare. The evidence linking maternal age to the utilisation of SBA is inconclusive. ${ }^{123536}$

This article analyses the determinants of adherence to the full continuum of maternal care using prospective cohort data of 5879 pregnant women in Kenya. The data were collected in real-time through a digital health platform, generating high-quality data that were less prone to recall bias compared with standard self-reported retrospective survey data on maternal care utilisation. ${ }^{38}$

\section{METHOD}

\section{Conceptual framework for adherence to maternal care}

This study is based on a conceptual framework adapted from Andersen's model of health services utilisation. ${ }^{39}$ Andersen's model explains healthcare utilisation with contextual and individual characteristics, health behaviours and outcomes. Our study focuses on the individual rather than the contextual aspects, using individual care journey data to understand the basis of women's behaviour in using maternal care. 


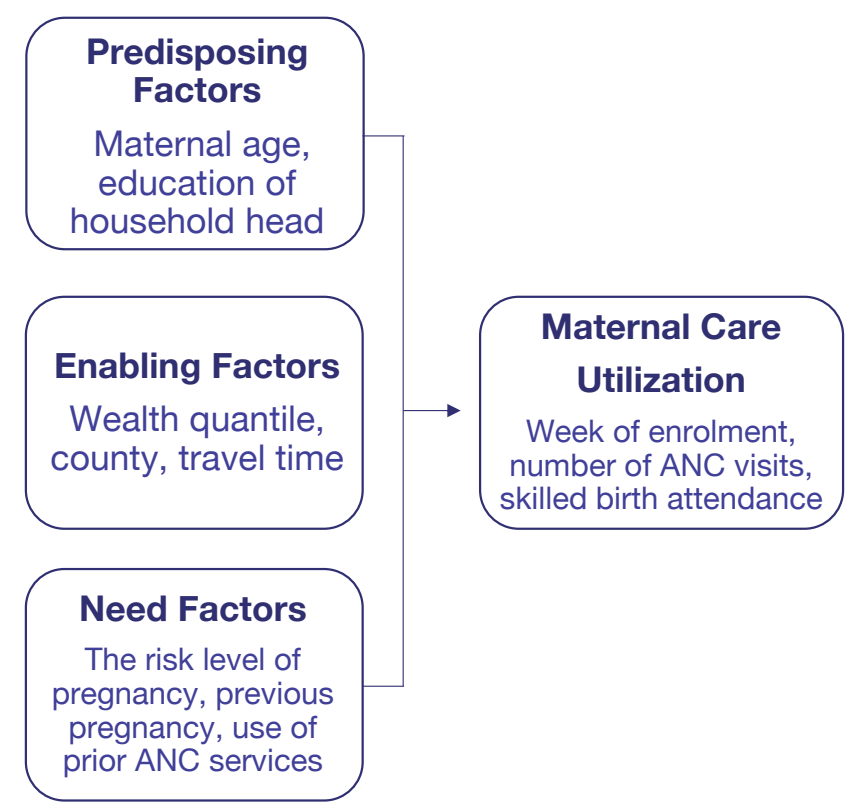

Figure 1 The conceptual framework for adherence to maternal care. ANC, antenatal care. Conceptual framework adapted from Andersen's framework.

Figure 1 shows the adapted framework. Healthcare utilisation is mainly influenced by three categories of individual characteristics: predisposing, enabling and need factors. ${ }^{39}$ Predisposing factors indirectly influence the use of health services, encompassing demographics and social factors such as gender, age, education, occupation, ethnicity, social network and health beliefs. Predisposing factors available for our analysis are the mother's age at conception and the household head's education level. Enabling variables expedite or impede the use of healthcare services. The enabling factors used in this study are wealth status, county indicators and travel time to the facility. Need factors play a fundamental role in the use health services. They capture health-related determinants of the woman's decision to seek maternal care. This encompasses perceived needs, capturing subjective perceptions about the required health services during pregnancy, as well as evaluated needs, referring to professional and objective measurements, diagnoses and estimated risk levels of the pregnancy. ${ }^{39}$ The need factors included in the analysis are the risk level as diagnosed by a health professional during pregnancy, having had a previous pregnancy and prior utilisation of maternal care services.

\section{Study setting}

Kenya is classified as a lower-middle-income country. The country's total population size was estimated to be 48 million in 2019 , with $50.5 \%$ women, of which $57.5 \%$ were of reproductive age. ${ }^{40}$ The study is based on data gathered from three counties: Nairobi (urban, estimated population 4.3 million), Kisumu (relatively periurban, estimated population 1.2 million of which $61.8 \%$ rural) and Kakamega (mostly rural, estimated population 1.9 million of which $90.0 \%$ rural). In combination, they provide a diverse overview of the maternal health-seeking behaviour of pregnant women in both rural and urban areas.

The MMR in Kenya is $62 \%$ higher than the world average. ${ }^{4}$ In 2014 , only $19.8 \%$ of Kenyan mothers initiated their ANC visits in the first trimester. ${ }^{41}$ Coverage of the recommended four ANC visits was $57.6 \% .^{15}$ In 2019 , $85.7 \%$ of pregnant women gave birth at a healthcare facility using SBA. ${ }^{42}$ Almost $40 \%$ of all neonatal deaths in Kenya are related to inadequate check-ups for pregnancy complications. ${ }^{43}$ Attending at least two ANC visits has been shown to decrease the probability of a stillbirth by half in Kenya. ${ }^{44}$

The data are drawn from the MomCare project, which incentivises 'access and adherence to care'-journeys through a digitally enabled 'smart contract'. As an initiative of the PharmAccess Group, MomCare enrols pregnant women in a partly or fully subsidised health insurance programme, offering a 'health wallet' on their mobile phone, which they can use to check-in and pay at a selected network of clinics. The health wallet runs on a mobile platform (m-tiba ${ }^{45}$ by Carepay Limited ${ }^{46}$ ) that enables the MomCare analytics engine to collect realtime medical data, send reminders for check-ups and nudges to women to use care, and reward providers financially for quality care provision when women complete their maternal care journey. As such, MomCare promotes transparency over pregnancy status, delivered care and funds allocation across all agents (patients, providers, payers) during the entire care process.

MomCare started in November 2017 and was operating in 25 health facilities by the end of the study period in August 2020. These facilities were connected to the m-tiba platform and received support through SafeCare, a quality improvement programme. ${ }^{47}$ The MomCare bundle covers the following basic maternal care services: four ANC consultations with related lab tests and vitamin complements, ultrasound scan, extra clinic consultations to treat pregnancy-related complications, normal and complicated delivery, two post-natal care consultations and three immunisations for the newborn.

\section{Research design and sampling methodology}

The study is designed as a prospective cohort study covering the period of February 2019 to August 2020. The study sampling frame includes all pregnant women who presented at one of the MomCare clinics during the study period, and who were eligible for the MomCare program. According to the eligibility criteria, enrolment should take place within the first 26 weeks of pregnancy, except for teenagers who could enrol at any pregnancy stage. Data were only collected from MomCare clinics, precluding a comparison with non-MomCare clinics.

Eligible women presenting at the health facilities are onboarded on MomCare as follows: they register, 
receive information on the MomCare bundle, consent to participate, and participate in a baseline survey. In total, 11538 eligible women enrolled in one of the 25 MomCare-connected clinics since programme inception in November 2017 (see online supplemental figure A1 for the sampling strategy). The study period starts from February 2019 onwards, because the baseline questionnaire was not standardised before that moment. As a result, 856 women who enrolled before February 2019 $(7.4 \%)$ were excluded from the study sample. To be able to conduct the analyses of enrolment, ANC visits and SBA on the same sample of women, we excluded 4799 women $(40.5 \%)$ from the sample without SBA information (whose pregnancy was less than 42 weeks in August 2020, and who had not yet delivered in a MomCare clinic). This yields a sample of 5883 women between 13-49 years. Missing observations in one or more outcome variables reduce the final sample further to 5879 . With this sample size, the analysis is powered (at $\beta=0.80$ and $\alpha=0.05$ ) to correctly estimate the week of enrolment within 0.2 weeks of the true population average, the number of ANC visits within 0.05 visits of the true population average, and SBA within $4.0 \%$ of the true population average. ${ }^{48}$

\section{Data collection}

The analysis is based on the data collected through the MomCare analytics engine, that is, data collected from the survey at enrolment as described in the Study setting section, and throughout the mother journey via the medical information submitted on m-tiba by the healthcare providers. ${ }^{49}$ Key advantages of using realtime data collected through the analytics engine are the reduced recall bias and increased probability of accurate reporting, ${ }^{380}$ especially when compared with data based on, for example, Demographic and Health Surveys that rely on women's retrospective self-reports with recall periods of up to 5 years. ${ }^{51}$

The MomCare baseline survey recorded information about women's demographic and socioeconomic characteristics, including age, education of the household head, household size, dwelling information, wealth indicators, and parity as well as obstetric history. Medical records in the MomCare analytics engine contain information about the week of enrolment; the number of ANC visits; diagnoses, drugs and tests associated with each ANC visit; risklevel of the pregnancy; type of delivery and complications during delivery.

\section{Variables}

The analyses are based on three primary outcome variables: the week of enrolment at a MomCare clinic, the total number of ANC visits at a MomCare clinic and having a skilled delivery at a MomCare clinic. The data do not capture visits at non-MomCare facilities. The first visit at the MomCare clinic of 142 women was recorded as a normal check-up rather than an ANC visit. These observations are kept in the dataset but not counted as an ANC visit in the analyses. Explanatory variables are classified into predisposing, enabling and need factors in line with the adapted conceptual framework in figure 1.

\section{Predisposing factors}

Age is included as a continuous variable. Education level is a categorical variable measuring the highest completed education level of the household head (at most primary completed, at most secondary completed, tertiary completed).

\section{Enabling factors}

A wealth index was created based on the first loading of a principal component analysis on the total sample using data on households' ownership of selected assets and dwelling characteristics, presence of electricity, education of household head, household size and means of transportation to the clinic. The population was then ranked based on the wealth index and assigned to three wealth terciles: low, middle and high. Distance to the clinic was measured as a dummy variable equal to 1 for travel time greater than $30 \mathrm{~min}$. County indicators were included for Nairobi, Kisumu and Kakamega (as proxies for urban, periurban and rural).

\section{Need factors}

The pregnancy risk level is included as a categorical variable, ranging from low risk ${ }^{1}$ for normal pregnancy without any additional complications, medium risk ${ }^{2}$ for pregnancies with non-life-threatening diagnoses (such as urinary tract infections or gestational diabetes) to high risk $^{3}$ for severe conditions. The risk level is determined by healthcare professionals at MomCare facilities based on medical diagnosis; it measures the maximum risk level attained at any point during enrolment. ${ }^{49}$ We emphasise that low-risk pregnancies still require the recommended minimum of four ANC visits. Furthermore, "previously pregnant' is a dummy variable equal to 1 if the woman had been pregnant before (multigravida).

\section{Statistical methods}

The analysis investigates four main research questions, that is, what are the determinants of (i) week of enrolment, (ii) number of ANC visits, and (iii) SBA and (iv) how are these outcomes interrelated? The analysis first estimates separate regressions for each of the three outcomes. The model's parameters are predicted with ordinary least square (OLS) regression, Poisson regression and logistic regression, respectively. Poisson regression is suitable to estimate equation 2 since the null hypothesis of the goodness-of-fit $\chi^{2}$ chi-squared test (H0: $\mathrm{X} \sim$ Poisson) is not rejected. In addition, the mean and variance of the ANC variable (2.971 and 2.975, respectively) show that the dependent variable is not over-dispersed and does not have an excessive number of zeros. The analyses subsequently introduce subsets of explanatory variables (predisposing, enabling and need factors) in a stepwise manner to control for potential confounding effects. Finally, the simultaneous 
relationships between the three outcome variables are assessed with structural equation modeling (SEM), using the same estimation methods and explanatory variables as for the separate regressions.

The determinants of the week of enrolment, the number of ANC visits and utilisation of SBA are estimated with the following consecutive specifications:

Enrolment Week $_{\mathrm{i}}=\beta_{0}+\beta_{\mathrm{j}} \mathrm{X}_{\mathrm{i}}+\mathrm{u}_{\mathrm{i}}$

$$
\begin{aligned}
\log \left(\mathrm{ANC}_{\mathrm{i}}\right)=\delta_{0}+\delta_{1} \text { Enrolment Week }_{\mathrm{i}}+\delta_{\mathrm{j}} \mathrm{X}_{\mathrm{i}}+\mathrm{v}_{\mathrm{i}} \\
\log \left(\mathrm{p}\left(\mathrm{SBA}_{\mathrm{i}}\right) / 1-\mathrm{p}\left(\mathrm{SBA}_{\mathrm{i}}\right)\right)=\begin{array}{r}
\gamma_{0}+\gamma_{1} \text { Enrolment Week }_{\mathrm{i}}+ \\
\gamma_{2} \mathrm{ANC}_{\mathrm{i}}+\gamma_{\mathrm{j}} \mathrm{X}_{\mathrm{i}}+\epsilon_{\mathrm{i}}
\end{array}
\end{aligned}
$$

Where the subscript $\mathrm{i}$ indicates the individual. The variables included in $\mathrm{X}_{\mathrm{i}}$ are age, education of household head, wealth tercile, distance to clinic dummy, county indicators, pregnancy risk level and previously pregnant, as described in the Variables section. $\mathrm{u}_{\mathrm{i}}, \mathrm{v}_{\mathrm{i}}$ and $\varepsilon_{\mathrm{i}}$ are the individual error terms. Standard errors (SEs) are robust to allow for heteroscedasticity.

To capture the continuum of care, the interrelationship between the week of enrolment, the number of ANC visits and utilisation of SBA is predicted with the following system of SEM equations:

$$
\begin{aligned}
& \log \left(\mathrm{ANC}_{\mathrm{i}}\right)=\mathrm{a}_{0}+\mathrm{a}_{1} \text { Enrolment Week }_{\mathrm{i}}+\mathrm{a}_{\mathrm{j}} \mathrm{X}_{\mathrm{i}}+\psi_{\mathrm{i}} \\
& \log \left(\mathrm{p}\left(\mathrm{SBA}_{\mathrm{i}}\right) / 1-\mathrm{p}\left(\mathrm{SBA}_{\mathrm{i}}\right)\right)= \mathrm{b}_{0}+\mathrm{b}_{1} \text { Enrolment Week }_{\mathrm{i}}+ \\
& \mathrm{b}_{2} \mathrm{ANC}_{\mathrm{i}}+\mathrm{b}_{\mathrm{j}} \mathrm{X}_{\mathrm{i}}+\xi_{\mathrm{i}}
\end{aligned}
$$

Where $\psi_{\mathrm{i}}$ and $\xi_{\mathrm{i}}$ are the individual error terms, and SEs are robust. All analyses are carried out using Stata V.16.0.

\section{Patient and public involvement}

Each pregnant participant voluntarily consented to join MomCare. MomCare made use of learnings deriving from the collected data and the providers' experiences to adapt the care bundle to the mothers' needs. Providers interacted directly with the mothers communicating about MomCare.

\section{RESULTS}

Table 1 panels (A-C) show the descriptive statistics of the study sample. The average age was 27.0 years (range 13-49). Thirty-three per cent of household heads completed at most primary education; $22 \%$ had a tertiary degree. The average household had 3.9 members. Thirty-one per cent of the sample was classified as poor, while the proportions in the middle and rich terciles were $35 \%$ and $33 \%$, respectively. Slightly more than a quarter, $27 \%$, lived in rural Kakamega, while $37 \%$ were located in periurban Kisumu. The remaining $36 \%$ were living in Nairobi. Women took $26 \mathrm{~min}$ on average to travel to the clinic (range 1-350), with half of them choosing to come on foot. Overall, $41 \%$ of pregnancies were classified as

\begin{tabular}{|c|c|c|c|}
\hline Variable & Obs. & Mean or $\%$ & SD \\
\hline \multicolumn{4}{|c|}{ Panel A: Sociodemographic characteristics } \\
\hline Maternal age & 5838 & 27.0 & 6.048 \\
\hline \multicolumn{4}{|c|}{ Education of household head } \\
\hline Primary (\%) & 5867 & 33.4 & \\
\hline Secondary (\%) & 5867 & 44.6 & \\
\hline Tertiary/college (\%) & 5867 & 22.0 & \\
\hline Household size & 5861 & 3.9 & 1.695 \\
\hline \multicolumn{4}{|l|}{ Wealth status } \\
\hline Low (\%) & 5814 & 31.7 & \\
\hline Middle (\%) & 5814 & 34.9 & \\
\hline High (\%) & 5814 & 33.3 & \\
\hline
\end{tabular}
'high risk', and $35 \%$ of women were primigravida.

Table 1 panel $\mathrm{D}$ shows that, on average, pregnant women enrolled in their 23rd week of pregnancy. Week of enrolment ranged from week 1 to week 48, with a modal value
Table 1 Descriptive statistics of the sample

\begin{tabular}{|c|c|c|c|}
\hline 1 (low risk) (\%) & 5877 & 32.7 & \\
\hline 2 (medium risk) (\%) & 5877 & 26.2 & \\
\hline 3 (high risk) (\%) & 5877 & 41.1 & \\
\hline \multicolumn{4}{|l|}{ Was woman pregnant before? } \\
\hline Primigravida (\%) & 5833 & 35.2 & \\
\hline Multigravida (\%) & 5833 & 64.8 & \\
\hline \multicolumn{4}{|c|}{ Panel D: Primary outcome variables } \\
\hline Week of enrolment & 5879 & 22.8 & 6.821 \\
\hline Number of ANC visits & 5879 & 3.0 & 1.724 \\
\hline Skilled birth attendance (\%) & 5879 & 58.4 & \\
\hline
\end{tabular}

Panel B: Geographic characteristics

County

\begin{tabular}{llll} 
Kakamega (\%) & 5807 & 26.7 & \\
Kisumu (\%) & 5807 & 37.3 & \\
Nairobi (\%) & 5807 & 36.0 & \\
Travel time (in minutes) & 5766 & 25.7 & 16.987 \\
\hline $\begin{array}{l}\text { Transportation } \\
\text { By foot (\%) }\end{array}$ & 5871 & 49.5 & \\
Other means (\%) & 5871 & 50.5 &
\end{tabular}

Panel C: Pregnancy characteristics

The risk level of pregnancy

Based on a full analysis sample of 5879 women enrolled in the MomCare programme. The table shows the descriptive statistics (number of observations (Obs.), mean, standard deviation (SD) for continuous variables; number of observations and proportion for categorical variables (\%)) for the outcome and explanatory variables used in the analysis.

ANC, antenatal care.

of 24 weeks (figure 2A). Women attended on average 3.0 ANC visits with range $0-10$ and mode 1 (figure 2B). Finally, $58.4 \%$ of women delivered at a MomCare clinic in the presence of a skilled birth attendant.

Table 2 shows the results of the OLS regression of week of enrolment on the enabling, predisposing and need factors in columns 1-3, respectively. Covariates were added to the model in three consecutive steps. Except for the coefficient on education of the household head, the explanatory variables were robust to the inclusion of additional confounders. According to column 3 (preferred specification), pregnant 

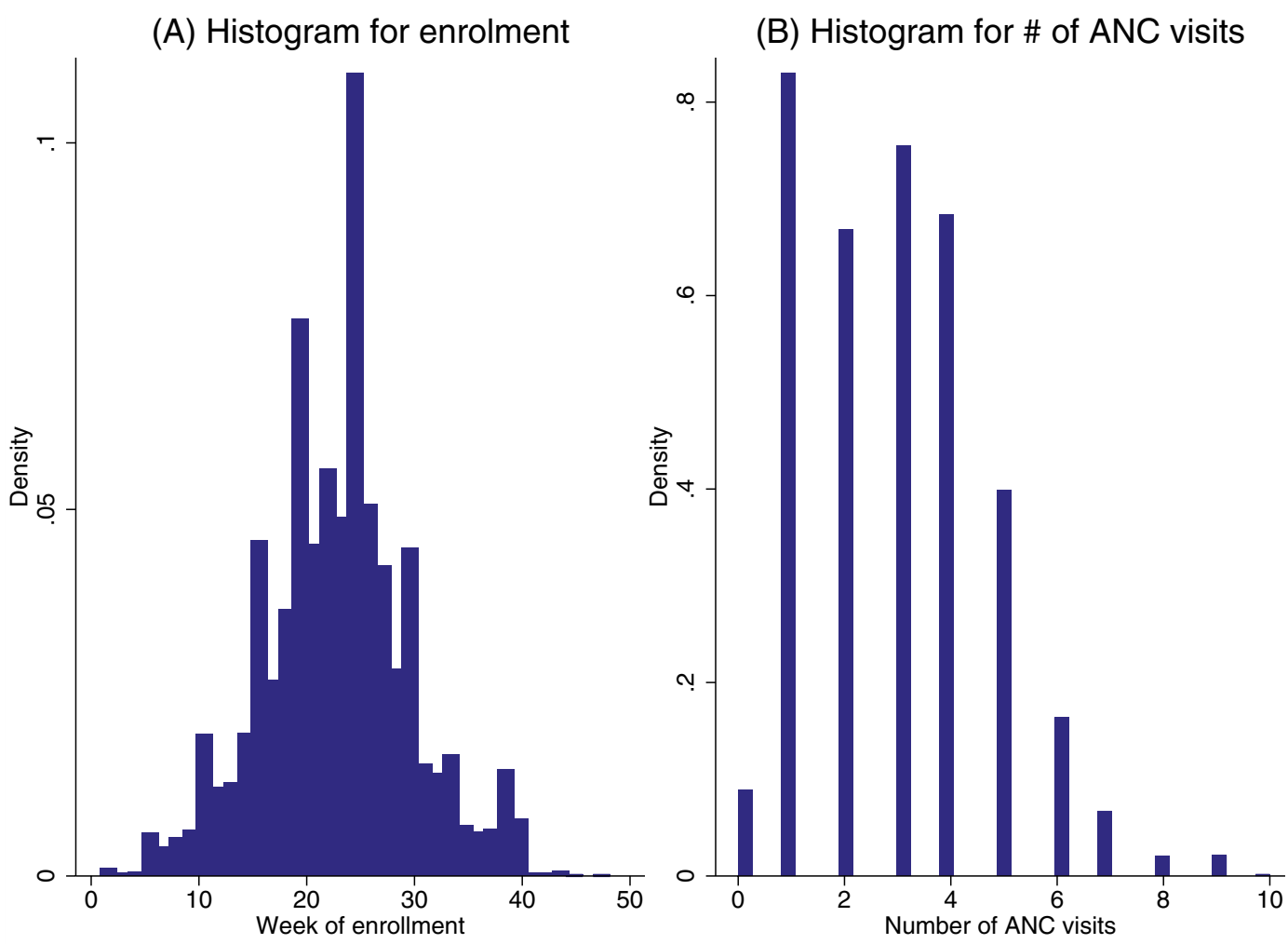

Figure 2 Histograms for week of enrolment and number of ANC visits. ANC, antenatal care. Based on the full analysis sample of 5,879 women enrolled in the MomCare program. The left -hand panel shows a histogram of the week of the first enrolment at a MomCare clinic. The right -hand panel shows a histogram of the total number of ANC visits at a MomCare clinic.

women were more likely to enrol early in ANC if they were older ( $\beta=-0.12,95 \%$ Confidence Interval (CI) -0.16 to $-0.08)$, had a household head with completed tertiary education $(\beta=-0.59,95 \% \mathrm{CI}-1.16$ to -0.03$)$, belonged to the middle or high wealth tercile $(\beta=-1.26,95 \% \mathrm{CI}-1.75$ to -0.76 and $\beta=-1.31,95 \% \% \mathrm{CI}-1.87$ to -0.74 , respectively), lived in Kakamega ( $\beta=-0.72,95 \%$ CI -1.20 to -0.24$)$, were multigravida ( $\beta=-0.44,95 \% \mathrm{CI}-0.90$ to 0.03$)$ and had a middlerisk or high-risk pregnancy $(\beta=-1.48,95 \% \mathrm{CI}-1.91$ to -1.05 ; and $\beta=-1.04,95 \% \mathrm{CI}-1.45$ to -0.64 , respectively). On the other hand, living in Kisumu ( $\beta=0.83$, 95\% CI 0.38 to 1.28 ) and at a long distance from the clinic ( $\beta=0.68,95 \%$ CI 0.32 to 1.04) were associated with late enrolment in ANC.

Table 2 columns $4-7$ show the incidence rate ratios (IRRs) of the Poisson regressions. An IRR $>1$ indicates that the incidence rate of ANC visits increases with a one unit increase in the independent variable. The number of ANC visits was significantly associated with late enrolment and was robust to the inclusion of potential confounding variables. Our preferred specification in column 7 shows that every week of delayed enrolment in ANC reduced the number of ANC visits by $3 \%$ (IRR $=0.967,95 \% \mathrm{CI}$ 0.965 to 0.969$)$. A long distance to the clinic also reduced $\mathrm{ANC}$ visits (IRR $=0.96,95 \%$ CI 0.94 to 0.99 ). The number of ANC visits was positively associated with maternal age (IRR=1.004, 95\% CI 1.001 to 1.007 ), having a household head with secondary or tertiary education (IRR $=1.05$, $95 \%$ CI 1.01 to 1.08 ; and IRR=1.09, 95\% CI 1.04 to 1.14 , respectively), living in Kakamega (IRR=1.14, 95\% CI 1.10 to 1.18 ), being multigravida (IRR $=1.08,95 \%$ CI 1.04 to 1.11 ), and for medium-risk or high-risk pregnancies (IRR $=1.25,95 \%$ CI 1.21 to 1.30 ; and $\mathrm{IRR}=1.26$, 95\% CI 1.22 to 1.31, respectively). The number of ANC visits was not significantly associated with wealth.

Table 2 columns $8-11$ demonstrate that the stepwise inclusion of confounding variables does not significantly modify the relationship between SBA and the two main coefficients of interest (week of enrolment and number of ANC visits). An OR $>1$ indicates that the OR of using skilled delivery at MomCare clinics (vs not using) increases with a one unit increase in the independent variable. Our preffered estimation in column 11 shows that, the odds of using SBA at a MomCare clinic increased with each week of later enrolment and every additional $\mathrm{ANC}$ visit $(\mathrm{OR}=1.03,95 \% \mathrm{CI} 1.02$ to 1.04 ; and $\mathrm{OR}=1.28$, $95 \%$ CI 1.22 to 1.34 , respectively). The relative probability of using SBA was lower for women who were older ( $\mathrm{OR}=0.98,95 \%$ CI.97 to 0.99), whose household head had completed tertiary education $(\mathrm{OR}=0.81,95 \% \mathrm{CI} 0.67$ to 0.97 ), who belonged to the middle or high wealth tercile $(\mathrm{OR}=0.80,95 \% \mathrm{CI} 0.68$ to 0.94 ; and $\mathrm{OR}=0.77,95 \% \mathrm{CI}$ 0.64 to 0.92 , respectively), and who lived in Kakamega or Kisumu (OR=0.38, 95\% CI 0.32 to 0.45 ; and $\mathrm{OR}=0.39$, $95 \%$ CI 0.34 to 0.46 , respectively). A longer travel time to the clinic $(\mathrm{OR}=1.26,95 \% \mathrm{CI} 1.11$ to 1.41$)$, being multigravida ( $\mathrm{OR}=1.46,95 \% \mathrm{CI} 1.26$ to 1.69$)$, and having a 


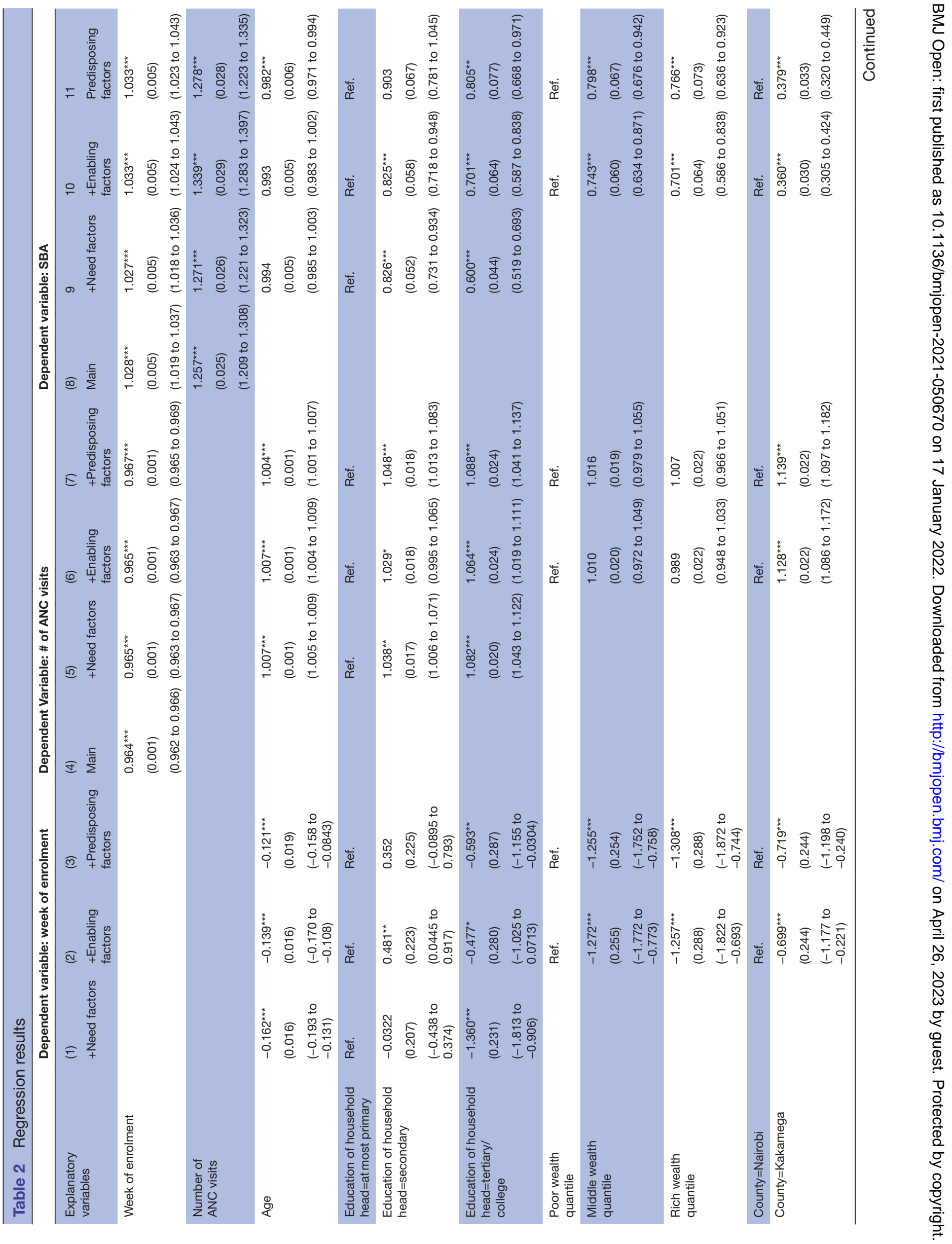




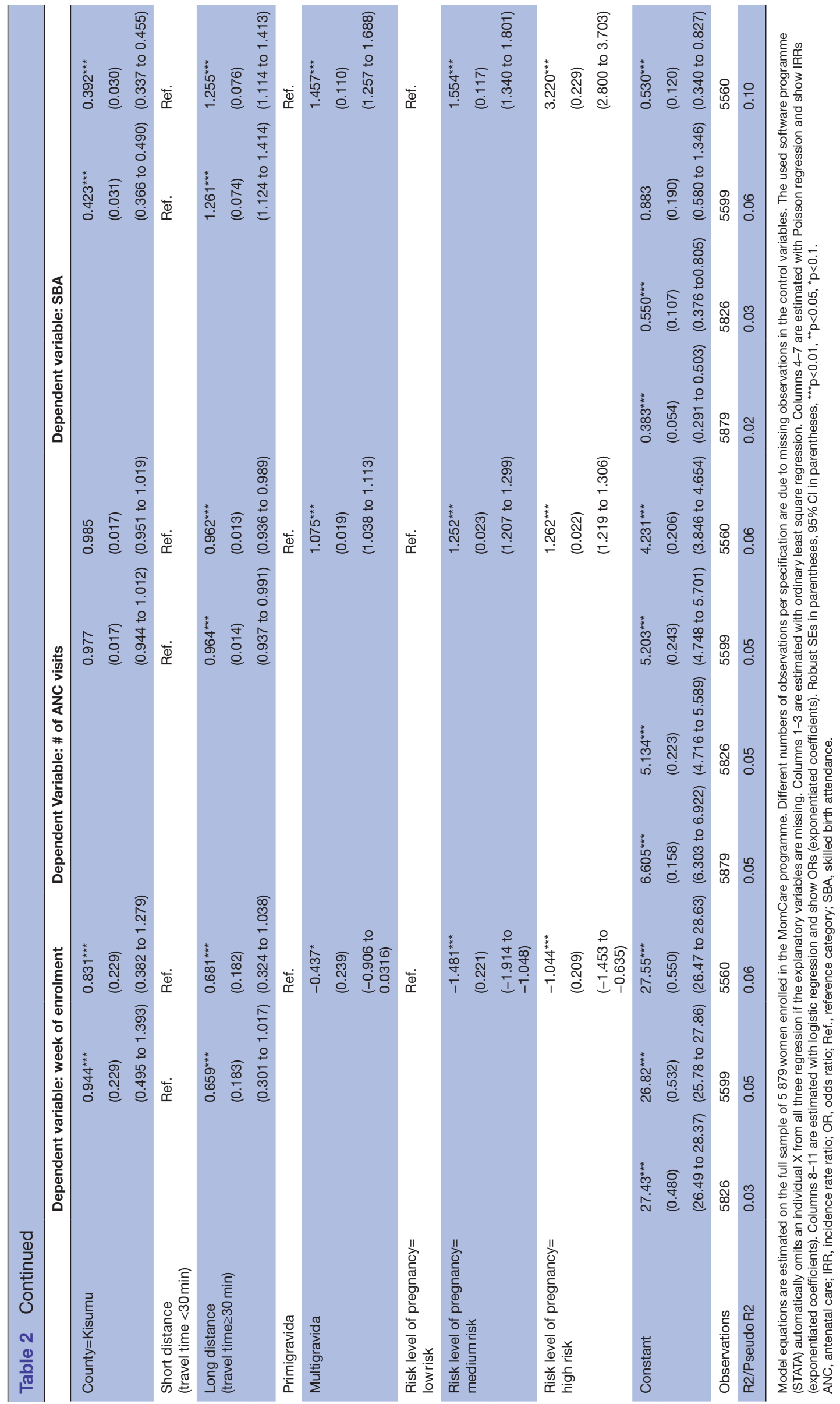




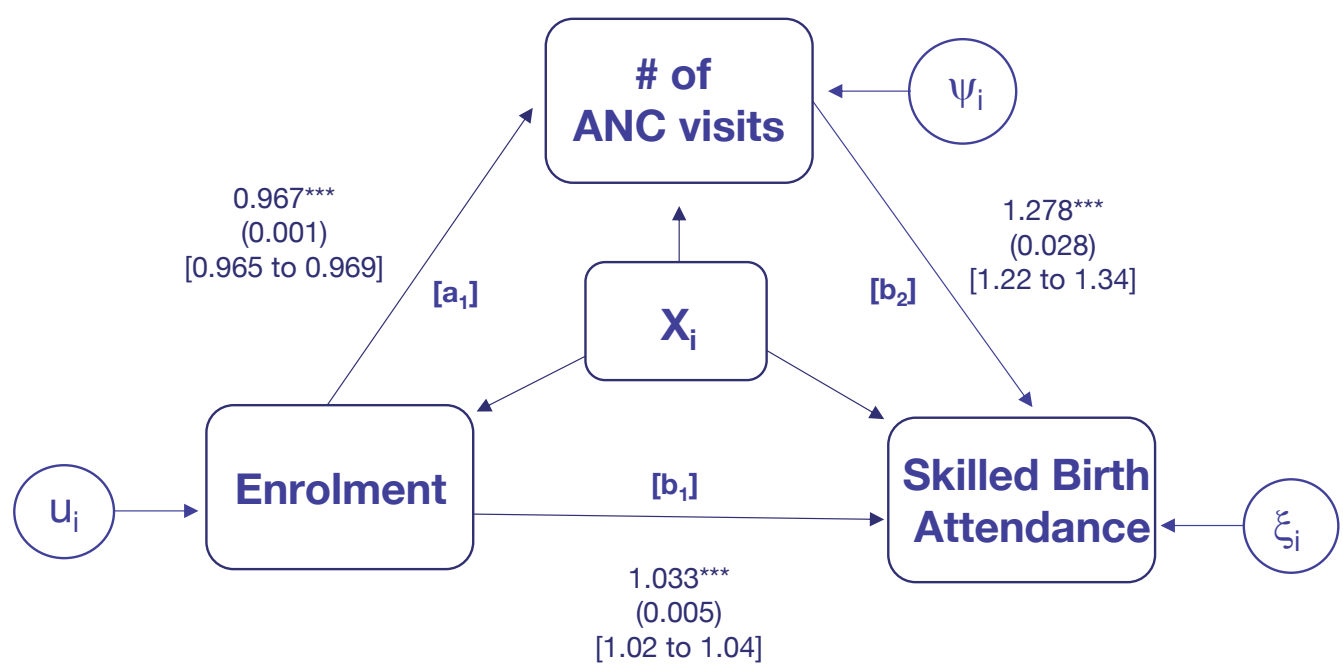

Figure 3 Structural equation modeling (SEM) results. The SEM is estimated on the full sample of 5,879 women. Path $\mathrm{a}_{1}$ is estimated with a Poisson regression as in Eq.4, while paths $b_{1}$ and $b_{2}$ are estimated with logistic regressions as in Eq.5. Variables included in $X_{i}$ are maternal age, education of the household head, wealth status, county, and travel time, plus the risk level of pregnancy. IRRs and ORs are given next to each path with robust standard errors in parentheses, $95 \% \mathrm{Cl}$ in square brackets. ${ }^{* \star *} p<0.01,{ }^{* *} p<0.05,{ }^{*} p<0.1$. ANC: antenatal care; IRR: incidence rate ratio; OR: odds ratio.

medium-risk or high-risk pregnancy $(\mathrm{OR}=1.55,95 \% \mathrm{CI}$ 1.34 to 1.80 ; and $\mathrm{OR}=3.22,95 \% \mathrm{CI} 2.80$ to 3.70 , respectively) were positively associated with the probability of SBA at a MomCare clinic.

The SEM estimates are summarised in figure 3. As in table 2 column 7, each week of delayed enrolment induced a $3 \%$ reduction in the number of ANC visits $\left(a_{1}, I R R=0.967,95 \%\right.$ CI 0.965 to 0.969$)$; while every additional ANC visit significantly increased the odds of SBA $\left(\mathrm{b}_{2}, \mathrm{OR}=1.28,95 \% \mathrm{CI} 1.22\right.$ to 1.34$)$ as in table 2 column 11. Indirectly, and holding all other explanatory variables constant, each week of delayed enrolment hence decreased the odds of SBA through a decrease in the number of ANC visits.

Simultaneously, the week of enrolment was directly and positively associated with SBA $\left(\mathrm{b}_{1}, \mathrm{OR}=1.033,95 \% \mathrm{CI}\right.$ 1.02 to 1.04). At least two potential confounders might cause this effect: the different health-seeking behaviours of teenagers versus adult women in our sample, and the heightened probability of complications when enrolling late. First, late enrolment in our sample was significantly correlated with being aged below 20 years $($ corr. $=0.263$, $p$ value $=0.000$ ). Moreover, teenagers were also more likely to have a high-risk pregnancy (corr. $=0.189$, $\mathrm{p}$ value $=0.000$ ) and-perhaps as a result-to deliver in a MomCare clinic (corr. $=0.044, \mathrm{p}$ value $=0.001)$. The direct association between late enrolment and SBA hence partially reflects the health-seeking behaviour of pregnant teenagers. Indeed, estimating the SEM model on the subsample of women aged 20 and above reduces the direct positive effect by $12 \%$ (to $b_{1}, O R=1.029,95 \%$ CI 1.02 to 1.04 ). Second, late enrolment might be associated with worse maternal health status at enrolment, leading to a greater need for a facility-based delivery towards the end of the journey. Although the data are indicative of a significant correlation between general pregnancy risk-levels and SBA (corr. $=0.264$, $p$ value $=0.000$ ), our dataset currently does not provide sufficient details on health risks at the time of enrolment to explore this mechanism further.

\section{DISCUSSION}

SSA accounts for two-thirds of all maternal deaths worldwide. The high MMR is associated with suboptimal adherence to the continuum of maternal care. To our knowledge, this study is the first to examine the three pillars of the continuum of maternal care (week of enrolment in ANC, number of ANC visits, utilisation of SBA) simultaneously, with data on 5879 pregnant women, and to analyse how the three key components of an adequate mother journey are interrelated. The study provides evidence of a domino-effect in adherence to maternal care. Each week of delayed enrolment decreases the number of ANC visits, and a lower number of ANC visits, in turn, significantly decreases the probability of SBA at a MomCare clinic. The findings highlight the importance of ensuring a sufficient number of ANC visits to fully benefit from maternal care until safe delivery. Early enrolment indirectly contributes to the probability of SBA through its effect on ANC visits.

On the other hand, delayed enrolment is also directly—and positively-associated with an SBA delivery. Exploratory analyses suggest that this partly reflects the relatively late enrolment of teenagers who are also more likely to have a high risk of complications and to deliver at a MomCare clinic. This hence underscores the heightened vulnerability of pregnant teenagers. The MomCare programme explicitly accounts for delayed teenage health-seeking behaviour by releasing the requirement of enrolling within the first 26 weeks of pregnancy for 
them. Second, the direct link between late enrolment and increased SBA could indicate a worse maternal health status at enrolment when enrolling late, which in turn would lead to a greater need for a facility-based delivery. These findings suggest that it might be beneficial to raise awareness among pregnant women about the link between early initiation of maternal care and good outcomes for mother and child. ${ }^{52}$ More in-depth research is needed, however, to provide conclusive evidence on the underlying mechanisms in this respect.

The analyses reveal systematic socioeconomic inequalities in access to maternal care: women in less educated and poorer households are at greater risk of late enrolment and a low number of ANC visits, in line with other Kenyan evidence. ${ }^{434}$ The study also shows that geographical accessibility to care was an essential determinant of the decision to initiate and continue ANC visits. Mothers who took more than half an hour to get to the clinic enrolled later for ANC and attended fewer visits than those who lived in proximity to the clinic. The cost of transportation, travel difficulties, and foregone time might discourage mothers from ANC utilisation. Therefore, one potential area of intervention is to increase accessibility, for example, through mobile clinics, mobile emergency services or telemedicine initiatives for routine check-ups. Such measures have become even more critical during the COVID-19 pandemic, given the risk of contagion and the travel restrictions that have been put in place. ${ }^{53}$

Unexpectedly, delivery at a MomCare clinic was lower for women from more educated and wealthier households, which could indicate that they choose to deliver elsewhere. ${ }^{164-57}$ This points to a notable limitation of the analysis, as the data do not capture maternal care sought at facilities other than those connected to the MomCare programme. Hence, our results might underestimate the actual number of ANC visits and SBA utilisation. The determinants of delivery location therefore merit further investigation. Future research would also benefit from including maternal education, as well as more comprehensive obstetric history data to examine in detail any non-linear effects of multiple pregnancies on adherence to care as well as potential complications during current and previous pregnancies.

In sum, our key findings highlight the importance of enrolling women as early as possible because this substantially affects the rest of their maternal journeys. At the same time, close monitoring of risky pregnancies, especially of teenagers, and raising concomitant awareness among expectant women seem paramount for enhancing SBA. The MomCare programme may contribute to the reduction of MMR not only by supporting women in accessing maternal care but also by collecting real-time data to assess and address risk, facilitate personalised maternal care and improve transparency. Additional research is needed to understand whether the enhanced opportunities for digital information provision positively influence women's decision to adhere to the full continuum of care, as well as to assess the impact thereof on maternal and child health outcomes.

Twitter Nursena Aksünger @nursenaaksunger and Teresa De Sanctis @ teredesteredes

Acknowledgements We are thankful to all the MomCare care providers and gratefully acknowledge all the MomCare team members' dedication across the PharmAccess offices in Kenya and the Netherlands. We are very thankful for the excellent editorial support by Professor Chacko Thomas.

Contributors TdS and WJ conceived the study; NA and TdS conducted a literature review; TdS and WJ designed the study; TdS, EW, RvD and MvdG developed data collection tools; NA analysed the data; NA drafted the manuscript; TdS and WJ reviewed the manuscript. NA is the guarantor. All authors made a critical review of the manuscript. All authors read and approved the final manuscript.

Funding This work was financially supported by the Health Insurance Fund of the Dutch Ministry of Foreign Affairs, Children's Investment Fund Foundation, MSD for Mothers, Stichting St. Antonius Foundation, Nationale Postcode Loterij and The Ministry of National Education of Turkey (internal project codes respectively 16001, $19005,19019,18011,16020$ and S29P78A3MACU9BC for funding of NA's research time).

Competing interests None declared.

Patient consent for publication Not applicable.

Ethics approval The ethical clearance for the research was given by the Amref Health Africa Ethics and Scientific Review Committee on 8 August 2019 with approval number: P679-2019. All the participants gave prior consent to participate in the programme, and they could withdraw from the study at any time. All data have been anonymised.

Provenance and peer review Not commissioned; externally peer reviewed.

Data availability statement Data are available upon reasonable request. Corresponding author: Nursena Aksünger, n.aksunger@vu.nl.

Supplemental material This content has been supplied by the author(s). It has not been vetted by BMJ Publishing Group Limited (BMJ) and may not have been peer-reviewed. Any opinions or recommendations discussed are solely those of the author(s) and are not endorsed by BMJ. BMJ disclaims all liability and responsibility arising from any reliance placed on the content. Where the content includes any translated material, BMJ does not warrant the accuracy and reliability of the translations (including but not limited to local regulations, clinical guidelines, terminology, drug names and drug dosages), and is not responsible for any error and/or omissions arising from translation and adaptation or otherwise.

Open access This is an open access article distributed in accordance with the Creative Commons Attribution Non Commercial (CC BY-NC 4.0) license, which permits others to distribute, remix, adapt, build upon this work non-commercially, and license their derivative works on different terms, provided the original work is properly cited, appropriate credit is given, any changes made indicated, and the use is non-commercial. See: http://creativecommons.org/licenses/by-nc/4.0/.

\section{ORCID iDs}

Nursena Aksünger http://orcid.org/0000-0002-7068-1505

Teresa De Sanctis http://orcid.org/0000-0002-6352-6195

Wendy Janssens http://orcid.org/0000-0002-2085-8608

\section{REFERENCES}

1 World Bank. Number of maternal deaths - World [Internet], 2017. Available: https://data.worldbank.org/indicator/SH.MMR.DTHS? locations $=1 \mathrm{~W} \&$ view=map [Accessed 20 Aug 2020].

2 World Health Organization, UNICEF, United Nations Population Fund, The World Bank. Trends in maternal mortality: 2000 to 2017. Geneva: WHO, 2019.

3 UNICEF Data Warehouse. Maternal death (estimated) [Internet], 2019. Available: https://data.unicef.org/topic/maternal-health/ maternal-mortality/

4 World Bank. Maternal mortality ratio (modeled estimate, per 100,000 live births) [Internet], 2017. Available: https://data.worldbank.org/ indicator/SH.STA.MMRT?locations=KE-1W-ZG [Accessed 20 Aug 2020].

5 Say L, Chou D, Gemmill A, et al. Global causes of maternal death: a who systematic analysis. Lancet Glob Health 2014;2:e323-33. 
6 Carroli G, Rooney C, Villar J. How effective is antenatal care in preventing maternal mortality and serious morbidity? an overview of the evidence. Paediatr Perinat Epidemiol 2001;15 Suppl 1:1-42.

7 Moller A-B, Petzold M, Chou D, et al. Early antenatal care visit: a systematic analysis of regional and global levels and trends of coverage from 1990 to 2013. Lancet Glob Health 2017;5:e977-83.

8 Lincetto O, Mothebesoane-Anoh S, Gomez P. Opportunities for Africa's Newborns: practical data, policy and programmatic support for newborn care in Africa. Geneva: World Health Organization, 2006: 51-62.

9 Kuhnt J, Vollmer S. Antenatal care services and its implications for vital and health outcomes of children: evidence from 193 surveys in 69 low-income and middle-income countries. BMJ Open 2017:7:e017122.

10 Dahiru T, Oche OM. Determinants of antenatal care, institutional delivery and postnatal care services utilization in Nigeria. Pan Afr Med J 2015;21:321.

11 De Allegri M, Tiendrebéogo J, Müller $\mathrm{O}$, et al. Understanding home delivery in a context of user fee reduction: a cross-sectional mixed methods study in rural Burkina Faso. BMC Pregnancy Childbirth 2015;15:330

12 Tarekegn SM, Lieberman LS, Giedraitis V. Determinants of maternal health service utilization in Ethiopia: analysis of the 2011 Ethiopian demographic and health survey. BMC Pregnancy Childbirth 2014:14:161

13 Graham WJ, Bell JS, Bullough CH. Can skilled attendance at delivery reduce maternal mortality in developing countries? In: Brouwere D, V, Van Lerberghe W, eds. Safe motherhood strategies: a review of the evidence. Antwerp: ITGPress, 2001: 97-130. ISBN: 90-76070-19-9. https://www.itg.be/Files/docs/shsop/shsop17.pdf\#page=105

14 Kikuchi K, Ansah EK, Okawa S, et al. Effective linkages of continuum of care for improving neonatal, perinatal, and maternal mortality: a systematic review and meta-analysis. PLoS One 2015;10:e0139288.

15 UNICEF Data Warehouse. Antenatal care 4+ visits - percentage of women (aged 15-49 years) attended at least four times during pregnancy by any provider [Internet], 2019. Available: https://data. unicef.org/resources/data_explorer/unicef_f $\mathrm{f}$ ?ag=UNICEF\&df= GLOBAL_DATAFLOW\&ver=1.0\&dq=.MNCH_ANC4.\&startPeriod= 2007\&endPeriod=2020 [Accessed 20 Aug 2020].

16 Mbugua S, MacQuarrie KLD. Determinants of maternal care seeking in Kenya. DHS Further Analysis Reports No 111 [Internet], 2018. Available: https://dhsprogram.com/publications/publication-fa111further-analysis.cfm [Accessed 10 Sep 2020].

17 Kisaka L, Leshabari S. Factors associated with first antenatal care booking among pregnant women at a reproductive health clinic in Tanzania: a cross sectional study. EC Gynaecology 2020;9 https:// ecommons.aku.edu/eastafrica fhs sonam/272/

18 Manyeh AK, Amu A, Williams J, et al. Factors associated with the timing of antenatal clinic attendance among first-time mothers in rural southern Ghana. BMC Pregnancy Childbirth 2020;20:47.

19 Tekelab T, Berhanu B. Factors associated with late initiation of antenatal care among pregnant women attending antenatal clinic at public health centers in Kembata Tembaro zone, southern Ethiopia. Science, Technology and Arts Research Journal 2014;3:108-15.

20 Yaya S, Bishwajit G, Ekholuenetale M, et al. Timing and adequate attendance of antenatal care visits among women in Ethiopia. PLOS One 2017:12:e0184934.

21 Banda I, Michelo C, Hazemba A. Factors associated with late antenatal care attendance in selected rural and urban communities of the copperbelt Province of Zambia. Medical Journal of Zambia 2012;39:29-36 https://www.ajol.info/index.php/mjz/article/view/ 110594

22 Tesfaye G, Chojenta C, Smith R, et al. Application of the AndersenNewman model of health care utilization to understand antenatal care use in Kersa district, eastern Ethiopia. PLoS One 2018;13:e0208729.

23 Okedo-Alex IN, Akamike IC, Ezeanosike OB, et al. Determinants of antenatal care utilisation in sub-Saharan Africa: a systematic review. BMJ Open 2019;9:e031890.

24 Zegeye AM, Bitew BD, Koye DN. Prevalence and determinants of early antenatal care visit among pregnant women attending antenatal care in Debre Berhan health institutions, central Ethiopia. Afr J Reprod Health 2013;17:130-6.

25 Adewuyi EO, Auta A, Khanal V, et al. Prevalence and factors associated with underutilization of antenatal care services in Nigeria: a comparative study of rural and urban residences based on the 2013 Nigeria demographic and health survey. PLoS One 2018;13:e0197324.

26 Dairo M, Owoyokun K. Factors affecting the utilization of antenatal care services in Ibadan, Nigeria. Benin Journal of Postgraduate Medicine 2010;12 https://www.ajol.info/index.php/bjpm/article/view/ 63387
27 Fagbamigbe AF, Idemudia ES. Wealth and antenatal care utilization in Nigeria: policy implications. Health Care Women Int 2017:38:17-37.

28 Gupta S, Yamada G, Mpembeni R, et al. Factors associated with four or more antenatal care visits and its decline among pregnant women in Tanzania between 1999 and 2010. PLoS One 2014;9:e101893.

29 Onasoga OA, Afolayan JA, Oladimeij BD. Factor's influencing utilization of antenatal care services among pregnant women in Ife Central LGA, Osun State Nigeria. Advances in Applied Science Research 2012;3:1309-15 https://www.imedpub.com/articles/ factors-influencing-utilization-of-antenatal-care-services-amongpregnantwomen-in-ife-central-Iga-osun-state-nigeria.pdf

30 Ekpenyong MS, Bond C, Matheson D. Challenges of maternal and prenatal care in Nigeria. J Intensive Crit Care 2019;05.

31 Wilunda C, Quaglio G, Putoto G, et al. Determinants of utilisation of antenatal care and skilled birth attendant at delivery in South West Shoa zone, Ethiopia: a cross sectional study. Reprod Health 2015;12:74.

32 Adamu YM, Salihu HM. Barriers to the use of antenatal and obstetric care services in rural Kano, Nigeria. J Obstet Gynaecol 2002;22:600-3.

33 Asundep NN, Carson AP, Turpin CA, et al. Determinants of access to antenatal care and birth outcomes in Kumasi, Ghana. J Epidemiol Glob Health 2013;3:279-88.

34 Myer L, Harrison A. Why do women seek antenatal care late? perspectives from rural South Africa. J Midwifery Womens Health 2003;48:268-72.

35 Atuoye KN, Amoyaw JA, Kuuire VZ, et al. Utilisation of skilled birth attendants over time in Nigeria and Malawi. Glob Public Health 2017;12:728-43

36 Creanga AA, Odhiambo GA, Odera B, et al. Pregnant women's intentions and subsequent behaviors regarding maternal and neonatal service utilization: results from a cohort study in Nyanza Province, Kenya. PLoS One 2016;11:e0162017.

37 Kazanga I, Munthali AC, McVeigh J, et al. Predictors of utilisation of skilled maternal healthcare in Lilongwe district, Malawi. Int $J$ Health Policy Manag 2019;8:700-10.

38 Das J, Hammer J, Sánchez-Paramo C. The impact of recall periods on reported morbidity and health seeking behavior. J Dev Econ 2012;98:76-88 https://www.sciencedirect.com/science/article/abs/ pii/S0304387811000708

39 Andersen RM, Davidson PL, Baumeister SE. Improving access to care. changing the US health care system: key issues in health services policy and management. San Francisco: Jossey-Bass, 2014: 36. 33-69.

40 Kenya National Bureau of Statistics. 2019 Kenya Population and Housing Census Volume III: Distribution of Population by Age, Sex and Administrative Units [Internet]. Available: https://www.knbs.or. $\mathrm{ke} /$ ?wpdmpro=2019-kenya-population-and-housing-census-volumeiii-distribution-of-population-by-age-sex-and-administrative-units [Accessed 08 Nov 2020].

41 Kenya National Bureau of Statistics, Ministry of Health/Kenya, National AIDS Control Council/Kenya, Kenya Medical Research Institute, National Council for Population and Development/Kenya, and ICF International. Kenya Demographic and Health Survey 2014 [Internet], 2014. Available: https://dhsprogram.com/Where-We-Work/ Country-Main.cfm?ctry_id=20\&c=Kenya\&Country=Kenya\&cn=\& $r=1$ [Accessed 10 Sep 2020].

42 Kenya National Bureau of Statistics. 2019 Kenya Population and Housing Census Volume IV: Distribution of Population by SocioEconomic Characteristics [Internet].. Available: https://www.knbs.or. $\mathrm{ke} /$ ? wpdmpro=2019-kenya-population-and-housing-census-volumeiv-distribution-of-population-by-socio-economic-characteristics [Accessed 08 Nov 2020].

43 Arunda M, Emmelin A, Asamoah BO. Effectiveness of antenatal care services in reducing neonatal mortality in Kenya: analysis of national survey data. Glob Health Action 2017;10:1328796.

44 Brown CA, Sohani SB, Khan K, et al. Antenatal care and perinatal outcomes in Kwale district, Kenya. BMC Pregnancy Childbirth 2008;8:2.

45 M-TIBA. M-TIBA Dashboard [Internet]. Available: http://pharmaccess. m-tiba.org/about [Accessed 07 Dec 2020].

46 CarePay. CarePay: Giving Everyone the Power to Care [Internet]. Available: https://www.carepay.com/ [Accessed 07 Dec 2020].

47 SafeCare. SafeCare [Internet]. SafeCare. Available: https://www.safecare.org/ [Accessed 07 Dec 2020].

48 Lemeshow S, Hosmer DW, Klar J, et al. Adequacy of sample size in health studies. England: John Wiley \& Sons, 1990.

49 World Health Organization. ICD-10 : international statistical classification of diseases and related health problems : tenth revision [Internet. 2nd ed. World Health Organization, 2004. https://apps. who. int/iris/handle/10665/42980 
50 Geng X, Janssens W, Kramer B, et al. Health insurance, a Friend in need? impacts of formal insurance and crowding out of informal insurance. World Dev 2018;111:196-210.

51 The DHS Program. Quality information to plan, monitor and improve population, health, and nutrition programs [Internet]. Available: https://dhsprogram.com/ [Accessed 30 Sep 2021].

52 Pell C, Meñaca A, Were F, et al. Factors affecting antenatal care attendance: results from qualitative studies in Ghana, Kenya and Malawi. PLoS One 2013;8:1-11.

53 Kimani RW, Maina R, Shumba C, et al. Maternal and newborn care during the COVID-19 pandemic in Kenya: re-contextualising the community midwifery model. Hum Resour Health 2020;18:10.1186/ s12960-020-00518-3.

54 Burns PA, Zunt JR, Hernandez B, et al. Intimate partner violence, poverty, and maternal health Care-Seeking among young women in Kenya: a cross-sectional analysis Informing the new sustainable development goals. Glob Soc Welf 2020;7:1-13.

55 Fotso J-C, Ezeh A, Madise N, et al. What does access to maternal care mean among the urban poor? factors associated with use of appropriate maternal health services in the slum settlements of Nairobi, Kenya. Matern Child Health J 2009;13:130-7.

56 Karanja S, Gichuki R, Igunza P, et al. Factors influencing deliveries at health facilities in a rural Maasai community in Magadi sub-County, Kenya. BMC Pregnancy Childbirth 2018;18:5.

57 van Eijk AM, Bles HM, Odhiambo F, et al. Use of antenatal services and delivery care among women in rural Western Kenya: a community based survey. Reprod Health 2006;3:10.1186/1742-47553-2. 